[2] Henderson CF, Seo P. Biologic agents in systemic vasculitis. Int J Clin Rheumtol. 2011; 6(4):453-462.

Acknowledgements: None

Disclosure of Interest: None declared

DOI: 10.1136/annrheumdis-2018-eular.5952

\section{AB0650 THROMBOTIC MICROANGIOPATHY ASSOCIATED TO ANCA-POSITIVES VASCULITIS: A FRENCH RETROSPECTIVE CASE CONTROL STUDY AND LITERATURE REVIEW}

A. Dellal, on behalf of Francine Barclay M.D, Jean Jacques. Boffa, Eric. Rondeau, Pierre Yves. Hatron, Christophe. Deligny, Stephane. Bally, Olivier. Fain, Paul. Coppo, Arsène. Mekinian, Saint-Antoine, Paris, 2 rheumatology, Montfermeil,3. HOPITAL MONTFERMEIL, MONTFERMEIL, France

Objectives: In this large nationwide French case-control study, we describe the features of TTP and ANCA-positive vasculitis; compare to vasculitis without associated TTP; describe the outcome and treatments.

Methods: We collected all cases with TTP and associated vasculitis. We conducted a literature review using PubMed, Web of Science, congress posters from January 2005 to August 2017 of PTT and ANCA-positive vasculitis.

A control group of MPA without TTP during all the disease foillow-up was extracted from the Saint Antoine and Montfermeil Hospital patients with vasculitis. Firstly we compared our PTT cases and the literature review cases and secondary with a control group ANCA vasculitis without MAT.

Results: 8 patients with MAT secondary to ANCA associated vasculitides were included in our French series $75 \%$ of Women with a median age 45 years, ${ }^{21-76}$ positive ANCA in $50 \%$ and $37.5 \%$ is MPO, BVSA score at 16 , FFS at 1 . In 10 literature cases $90 \%$ Women, a median age 60 years [17-77], positive ANCA in $100 \%$ and $30 \%$ is MPO, BVSA score at 39 , FFS at 1 .

The clinical features at the diagnosis of vasculitis were fever $(n=5 ; 62 \%)$, ENT involvement $(25 \%)$, kidney cresescnt glomerular involvment $(n=6 ; 75 \%)$ with kidney failure in joint involvement $(n=2 ; 25 \%)$ polyarthralgia type, with gastrointestinal involvement type mesenteric ischemia and pericarditis and lung involvement (nodules and alveolar haemorrhage) $(n=1 ; 12.5 \%)$, in one case each Median Creactive protein levels were at $49 \mathrm{mg} / \mathrm{L}$ [1-204], with creatininemia at $170 \mathrm{mg} / \mathrm{dl}$ [80-588]. ANCA were present in 4 patients (50\%), MPO in 3 cases (37.5\%). The time between the diagnosis of vasculitis and TTP was 9 months [0-51].

TTP features were: $\mathrm{Hb}$ at $7.8 \mathrm{~g} / \mathrm{dl}$ [4.8-10], LDH 1658 [777-3110], platelets 33000 [3000-1 25 000], haptoglobin at 0 [0-0.05], creatinine at 205 [80-757]. ADAMTS 13 levels were at 10 [1-138], and $x$ patients have normal ADAMTS13 levels, with anti ADAMTS 13 antibodies in 1 case. Plasma exchanges were done in all patients with median of 10 exchanges [4-23], 37.5\% are dialyzed.

Conclusions: In comparison to our cases, the literature patients have similar organs involvement, but median creatininemia levels and BVAS levels were higher in the literature cases. Considering TTP features, our cases have less frequent active vasculitis, less important creatinine levels and thus less recurs to kidney dialysis.

In vasculitis associated with TTP, there was no significant differences in organ involvements, BVAS and FFS scales values, laboratory data and ANCA levels. Only creatininemia as expected was higer in vasculitis associated with TTP (225 Mmol vs $150 \mathrm{Mmol}, \mathrm{p}=0.0044$ ).

Disclosure of Interest: None declared

DOI: 10.1136/annrheumdis-2018-eular.7467

\section{AB0651 FREQUENCY OF PULMONARY HYPERTENSION IN BEHÇET'S DISEASE}

B. Armagan ${ }^{1}$, M. Oksul ${ }^{2}$, Y.Z. Sener ${ }^{2}$, A. Sari ${ }^{1}$, A. Erden ${ }^{1}$, G.K. Yardimci ${ }^{1}$, L. Kilic ${ }^{1}$, U. Kalyoncu' ${ }^{1}$, O. Karadag', S. Apras Bilgen ${ }^{1}$, S. Kiraz ${ }^{1}$, I. Ertenli' ${ }^{1}$ A. Akdogan' ${ }^{1}$. ${ }^{1}$ Hacettepe University Faculty of Medicine, Department of Internal Medicine, Division of Rheumatology; ${ }^{2}$ Hacettepe University Faculty of Medicine, Department of Cardiology, Ankara, Turkey

Background: Behçet's disease (BD) is a systemic vasculitis that involvement of pulmonary arteries can be seen.

Objectives: The aim of this study was to determine the frequency and the causes of pulmonary hypertension $(\mathrm{PH})$ in patients with $\mathrm{BD}$.

Methods: We studied consecutively $154 \mathrm{BD}$ patients who were fulfilled the International Study Group criteria for diagnosis of BD. All patients were evaluated with transthoracic echocardiography (TTE) for the presence of $\mathrm{PH}$. BD patients were categorised according to the involved organs in 5 groups: group 1 mucocutaneus and articular, group 2 ocular, group 3 vascular, group 4 gastrointestinal and group 5 neurologic involvements. The presence of PH was defined as estimated SPAB $\geq 40 \mathrm{mmHg}$, by TTE. Every subject evaluated by a detailed medical history and physical examination was performed. Additional laboratory results were obtained from hospital file records.

Results: The mean age (SD) and the median (min-max) disease duration of the patients were $41.8 \pm 12.6$ years and $126(6-540)$ months respectively. PH was detected in $17(11 \%)$ BD patients. Only $9(52 \%)$ patients were symptomatic (NYHA FC >1). Left sided heart disease (Group II: $9(52 \%)$ patients) was the leading cause of $\mathrm{PH}$. Four (23\%) patients had group IV PH and $75 \%$ (3/4) were symptomatic. Diastolic dysfunction (DD) was found in $32(20.8 \%)$ patients and only 1 patient had systolic dysfunction. The number of patients with DD was significantly higher in patients with $\mathrm{PH}$ as compare to patients without $\mathrm{PH}(8(47.1 \%)$ vs 24 $(17.6 \%), p=0.005)$. There were no difference in demographic and clinical features of patients with and without $\mathrm{PH}$. Only acneiform lesion was more frequently in patients without $\mathrm{PH}$ as compare to patients with $\mathrm{PH}, \mathbf{p}=\mathbf{0 . 0 4 7}$ (table 1). There were no differences in frequency of PH in BD groups (table 2).

Abstract AB0651 - Table 1. Demographic and clinical characteristics features of Behçet disease

\begin{tabular}{|c|c|c|c|}
\hline & All & $\begin{array}{c}\text { sPAP }^{3} 40 \mathrm{~mm} \\
\text { HG }\end{array}$ & $\begin{array}{c}\mathrm{sPAP}<40 \mathrm{~mm} \\
\mathrm{HG}\end{array}$ \\
\hline Female, n (\%) & $62(40.3)$ & $6(35.3)$ & $56(40.9)$ \\
\hline Age, mean, SD & $41.8 \pm 12.6$ & $48.1 \pm 14.6$ & $41.0 \pm 12.1$ \\
\hline $\begin{array}{l}\text { Diseae duration (month), median (min- } \\
\max \text { ) }\end{array}$ & $\begin{array}{l}126(6- \\
540)\end{array}$ & $168(12-540)$ & $120(6-480)$ \\
\hline Smoking, n (\%) & $76(49.4)$ & $7(41.2)$ & $69(50.4)$ \\
\hline Never smoker & $47(30.5)$ & $5(29.4)$ & $42(30.7)$ \\
\hline Current smoker & $31(20.1)$ & $5(29.4)$ & $26(19.0)$ \\
\hline \multicolumn{4}{|l|}{ Ex-smoker } \\
\hline Oral ulcer, n (\%) & $154(100)$ & $17(100)$ & $137(100)$ \\
\hline Genital ulcer, n (\%) & $104(67.5)$ & $11(64.7)$ & $93(67.9)$ \\
\hline$E N, n(\%)$ & $64(41.6)$ & $7(41.2)$ & $57(41.6)$ \\
\hline Papulo-pustular lesion, $\mathrm{n}(\%)$ & $35(22.7)$ & $3(22.7)$ & $32(23.4)$ \\
\hline Acneiform lesion ${ }^{*}, \mathrm{n}(\%)$ & $105(68.2)$ & $8(47.1)^{*}$ & $97(70.3)^{*}$ \\
\hline Articular, n (\%) & $33(22.7)$ & $4(23.5)$ & $31(22.6)$ \\
\hline Uveitis, n (\%) & $75(48.7)$ & $9(52.9)$ & $66(48.2)$ \\
\hline Pathergy, n (\%) & $40(26)$ & $6(35.3)$ & $34(24.8)$ \\
\hline Vascular, n (\%) & $48(31.2)$ & $9(52.9)$ & $23(31.1)$ \\
\hline Neurologic, $n(\%)$ & $18(11.7)$ & $2(11.8)$ & $16(11.7)$ \\
\hline Gastrointestinal, n (\%) & $12(7.8)$ & $1(5.9)$ & $11(8.0)$ \\
\hline
\end{tabular}

SPAP: Systolic pulmonary artery pressure, EN: Erythema nodosum

Abstract AB0651 - Table 2. Behçet disease group distribution in the pulmonary hypertension patients

\begin{tabular}{lcccccc}
\hline $\begin{array}{l}\text { Behçet } \\
\text { disease } \\
\text { (n) }\end{array}$ & $\begin{array}{c}\text { Mucocutaneus } \\
\text { and } \\
\text { articular (39) }\end{array}$ & $\begin{array}{c}\text { Ocular } \\
(\mathbf{7 5 )}\end{array}$ & $\begin{array}{c}\text { Vascular } \\
\text { (48) }\end{array}$ & $\begin{array}{c}\text { Gastrointestinal } \\
(\mathbf{1 2})\end{array}$ & $\begin{array}{c}\text { Neurologic } \\
(\mathbf{1 8})\end{array}$ & $\mathrm{p}$ \\
\hline $\begin{array}{l}\text { SPAP } \\
{ }^{3} 40, \mathrm{n} \\
(\%)\end{array}$ & $2(5.1)$ & $9(12)$ & $9(18.8)$ & $1(8.3)$ & $2(11.1)$ & 0.413 \\
\hline
\end{tabular}

SPAP: Systolic pulmonary artery pressure

Conclusions: The most frequent cause of $\mathrm{PH}$ in $\mathrm{BD}$ patients was group II $\mathrm{PH}$. There were also significant number of patients with group IV $\mathrm{PH}$. Pulmonary endarterectomy may be an option of treatment in inactive patients with group IV $\mathrm{PH}$.

Disclosure of Interest: None declared

DOI: 10.1136/annrheumdis-2018-eular.6672

\section{AB0652 PET/MR IN LARGE-VESSEL VASCULITIS: CLINICAL VALUE FOR THE DIAGNOSIS AND ASSESSMENT OF DISEASE ACTIVITY}

C. Laurent ${ }^{1}$, L. Ricard ${ }^{1}$, I. Buvat ${ }^{2}$, O. Fain ${ }^{1}$, A. Mekinian ${ }^{1}$, M. Soussan ${ }^{2}$, on behalf of French «PET -inflammation» Network. ${ }^{1}$ Internal Medicine, Hôpital Saint-Antoine; ${ }^{2}$ Nuclear Medicine, Hôpital Avicenne, Paris, France

Background: The diagnosis and the activity determination could be challenging in large-vessel vasculitis (LVV).

Objectives: The aim of this study was to analyze the value of hybrid PET/MR in LVV.

Methods: All consecutive patients with LVV who underwent PET/MR were included. PET/MR patterns were defined as inflammatory in the case of positive PET (grade $=3$ ) and abnormal MR (stenosis and/or wall thickening) and fibrous in the case of negative PET (grade 1 or 2) and abnormal MR.

Results: Thirteen patients with median age at 67 years (23-87 years) and 10 (77\%) females were included, and underwent 18 PET/MR scans. Eleven PET/MR performed at diagnosis $(n=4)$ or relapse $(n=7)$ and 7 in patients in remission. 8/18 (44\%) had PET/MR inflammatory pattern and $3 / 18(17 \%)$ had fibrous pattern. PET/MR were normal in 2/10 (20\%) cases of TA versus 5/8 (62\%) cases of GCA 